\title{
Advances in seismic monitoring technologies
}

\author{
G Goldswain Institute of Mine Seismology, Australia
}

\begin{abstract}
There have been several significant advances in seismic monitoring technologies and methods applied in mines in the past decade. Ranging from optical vibration sensors, through to low power and small footprint nodal sensor technologies, to imaging methods using induced seismicity and ambient noise. These new technologies and methods are starting to be applied to a range of applications in the underground mining environment. To support the ever-widening range of applications, seismic instrumentation and monitoring systems are evolving. We discuss some of the more significant developments, such as combining conventional sensors with more exotic sensors to produce hybrid sensors, and how nodal sensing technologies have inspired more portable and lower-power hardware. Some examples of recent products from the Institute of Mine Seismology (IMS) stable are presented to demonstrate these new acquisition technologies and finally, a few real-world application examples are presented which showcase how novel data collection and processing methodologies are being used in underground mines by IMS.
\end{abstract}

Keywords: seismic monitoring, seismic sensors, distributed acoustic sensors, distributed sensors, nodal sensors, hybrid sensors, microseismic, passive seismic, tailings dam monitoring

\section{Introduction}

Rather than presenting a specific dataset or experiment, this paper provides an overview of some of the recent advances in seismic monitoring technologies and methods that are being used and developed by industry. Some of the technologies presented are not recent advancements per se, but the way they have been used and applied is novel. Existing and emerging technologies are presented and briefly discussed in the context of seismic monitoring in mines, but the level of detail is light and references are provided for further reading by the interested reader. It is hoped that an awareness of the technologies and methods can be raised and serve as a departure point for discussions of possible applications and practical use cases.

Examples of hardware and methods presented are predominantly developed by Institute of Mine Seismology (IMS) and the figures are produced using a variety of softwares ranging from open source Python libraries and Gnuplot to IMS Vantage.

Because many of the advances discussed involve sensing technologies, a brief overview of seismic sensor characteristics is provided. Some real-world applications in the form of case studies and results are presented at the end to show what is possible using the technologies presented in earlier sections.

\section{Seismic sensors}

Monitoring seismicity begins with the choice of seismic sensor. The sensor is the first, and arguably most important, component that seismic signals encounter as physical quantities are transduced from physical phenomena such as ground motion to a voltage, which is then sampled and ultimately ends up in electronic form in a database where waveforms can be processed to build up a seismological catalogue.

Any limitations or distortions introduced by the sensor are carried through the signal chain and data path, eventually having an effect on the catalogue data. The importance of choosing the appropriate sensor and/or understanding its limitations should therefore be clear. 


\subsection{Seismic sensor characteristics}

Seismic sensors are typically characterised (and distinguished) by:

- Measurement quantity: the physical quantity being measured, e.g. ground velocity, ground acceleration, strain rate, etc.

- Directionality: uniaxial (1D/1C), triaxial (3D/3C), rotational, etc.

- Measurement range: the difference between the highest and lowest measurement quantity which can be measured by the sensor.

- Dynamic range or noise: ratio of highest to lowest quantity which the sensor can measure, and because this ratio $(A / B)$ is usually a very large number, it is often expressed in decibels which is defined as $20 \log 10(A / B)$.

- Frequency response: how the sensor responds to the measurement quantity with respect to its frequency.

Unfortunately, no commercially available seismic sensor meets all the required characteristics of seismic monitoring in mines. That is to say, no sensor:

- Has a sufficiently wide dynamic range to measure the smallest and largest (100 mm/s using McGarr (1991) and Mendecki (1997)) expected levels of ground motions of interest in mines.

- Is inexpensive enough to be deployed in large numbers throughout a mine to achieve good network coverage of the entire mine.

- Has a wide enough frequency response to accurately measure the energy of the smallest, and potency of the largest seismic events (3-2000 Hz using Mendecki 2013, p. 169).

- Is compact enough to be routinely installed in standard-diameter production drill holes.

Figure 1 illustrates the theoretical differences between some of the more commonly used seismic sensors in mines.

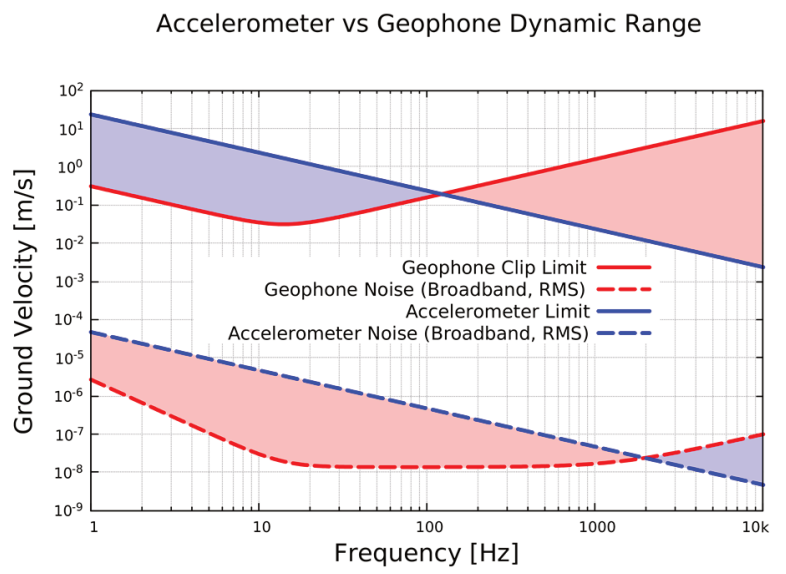

(a)

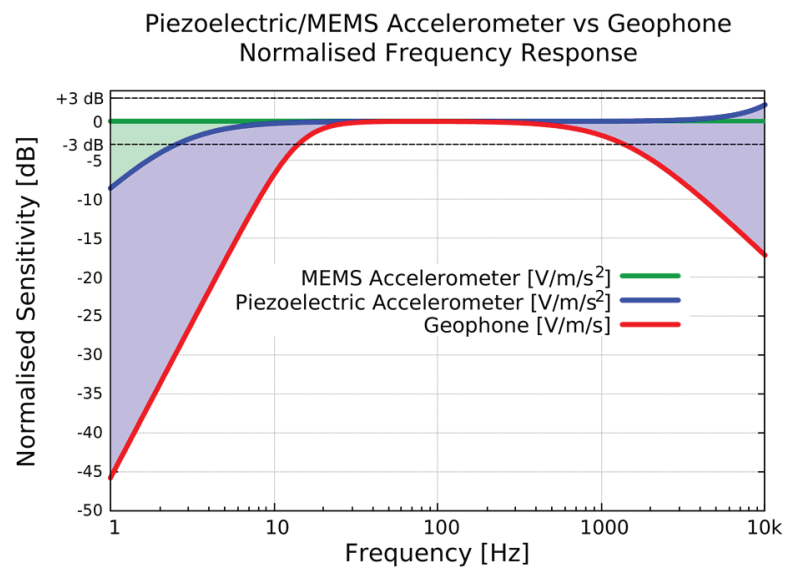

(b)

Figure 1 Theoretical sensor characteristics for common seismic sensors used in mines. (a) Dynamic range versus frequency of a $14 \mathrm{~Hz}$ geophone and accelerometer (broadband root mean square noise levels are based on datasheet figures and have been scaled by the sensitivity of the sensor); (b) Normalised sensitivity of a theoretical geophone, piezoelectric accelerometer and micro-electromechanical system (MEMS) accelerometer (reproduced from Goldswain 2018) 
The various non-overlapping regions of the plots shown in Figure 1 serve to illustrate the point that not all sensors cover the full range of characteristics which mine seismologists are interested in.

\subsection{Accelerometers versus geophones for in-mine seismic monitoring}

The two most commonly used sensors for in-mine microseismic monitoring are geophones and piezoelectric accelerometers, respectively. Their popularity is due to their relatively small size and low cost. Geophones are passive devices with low intrinsic noise, while piezoelectric accelerometers (simply referred to as 'accelerometers' hereafter) are more sensitive to the higher frequencies generated by smaller, closer seismic sources.

The inevitable question of 'which sensor should be used for seismic monitoring in mines' is often asked. To answer this question, in 2016, IMS designed an experiment in a Canadian mine where a small, dense array of geophones and accelerometers were installed in $10 \mathrm{~m}$ boreholes (Rebuli et al. 2017). The array consisted of seven sensor sites and each site consisted of a uniaxial $14 \mathrm{~Hz}$ geophone (sampled at 6,000 sps) and a co-located uniaxial $10 \mathrm{kHz}$ accelerometer (sampled at 24,000 sps). All sensor sites were configured with identical triggering settings.

The results were mostly as expected, but held some surprises. In summary, it was found that the higher sampling rate and sharper (higher frequency) arrivals of the accelerometers did not provide an advantage in picking and locating of blast events as velocity uncertainties dominated the location error. The accelerometers showed slightly higher estimates of both energy and potency for the smaller events. For energy, this was expected due to the accelerometers being more sensitive to the high frequency content of the smaller events. For potency, no reason was given but we believe that the accelerometers may be overestimating due to their inherently higher noise at low frequencies. The surprise came when comparing array sensitivities; while the geophones missed many of the smaller events with higher frequency content, the accelerometers missed some of the larger events as can be seen in Figure 2.

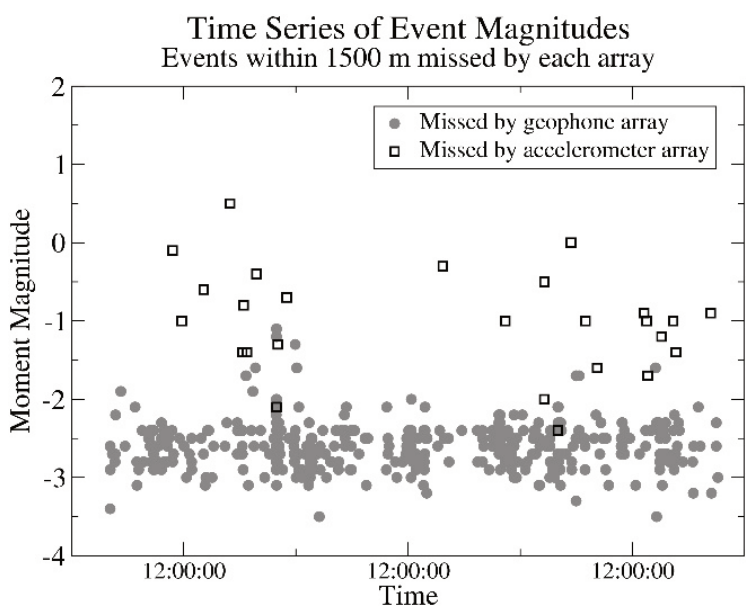

(a)

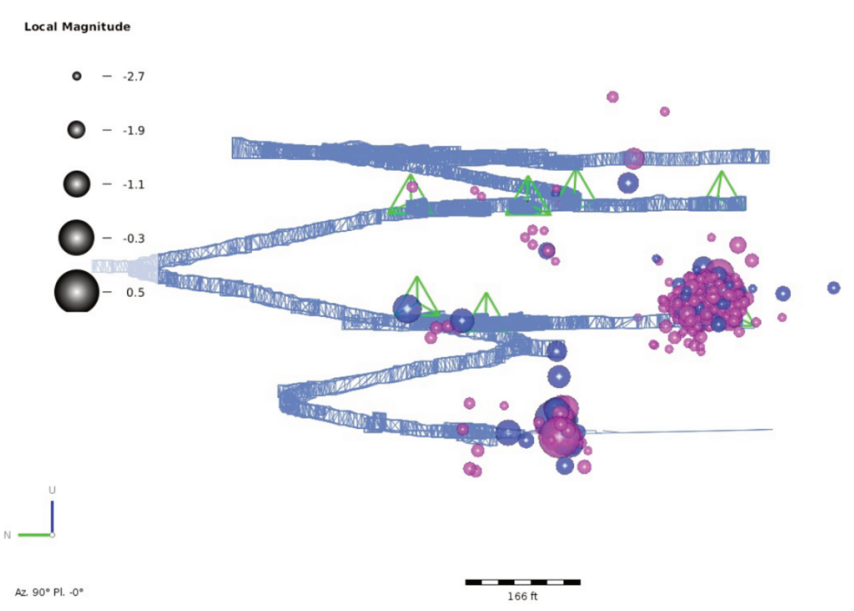

(b)

Figure 2 Events missed by the geophone and accelerometer arrays. (a) Plot of moment magnitude versus time of missed events from both arrays; (b) Missed events of (a) plotted in space (pink spheres are events recorded by the geophone array but missed by the accelerometers and vice versa for the blue spheres) (reproduced from Rebuli et al. 2017)

Figure 2 shows how the accelerometer array (surprisingly) missed medium sized events. This was attributed to the higher noise floor of the accelerometers and lower sensitivity of the accelerometers to lower-medium frequency signals.

The conclusion, and recommendation when choosing between geophones and accelerometers for seismic monitoring in mines, is that accelerometers excel in detecting small events in close proximity $(<100 \mathrm{~m})$ while 
geophones have very low noise so can detect more distant, medium sized events which fall below the accelerometer noise floor. Both sensors are useful, depending on the specific application and monitoring objectives. To benefit from the advantages of both sensor types, a hybrid array or array of 'hybrid sensors' (see Section 2.4) can be used.

\subsection{Strong ground motion sensors}

A common problem with many seismic sensors, geophones and accelerometers included, is their limited measurement range (see the solid upper lines in Figure 1a). Geophone measurement range is limited by the maximum displacement of its internal mass (typically $0.5-4 \mathrm{~mm}$ ), while the internal amplifiers of accelerometers become saturated at high signal levels. The effect is that large ground motions due to nearby seismic events results in distorted waveforms, which cannot be used for source characterisation or reliable peak ground motion or energy measurements. Figure 3 shows some examples of severely clipped waveforms due to nearby large events. Distortions due to clipping, however, are not always as obvious, which can lead to polluted catalogue data and misinterpretation.

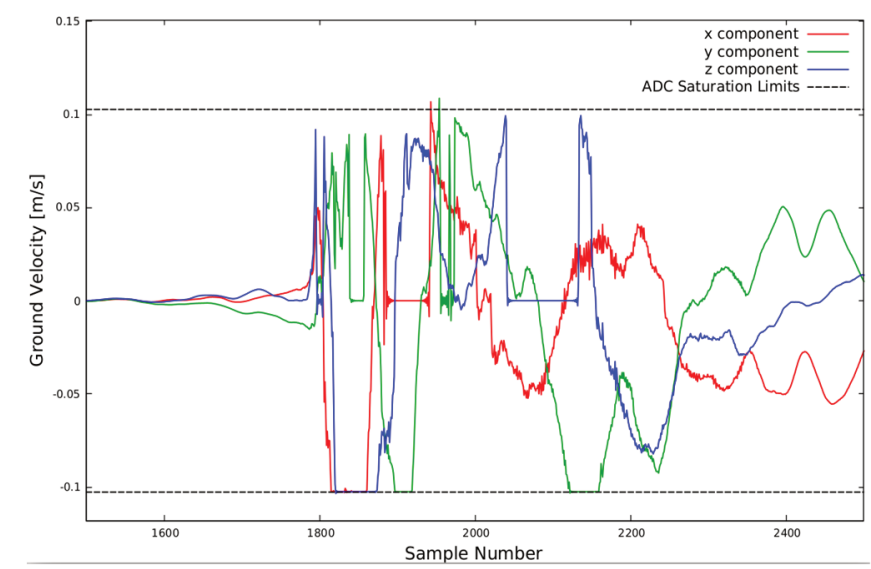

(a)

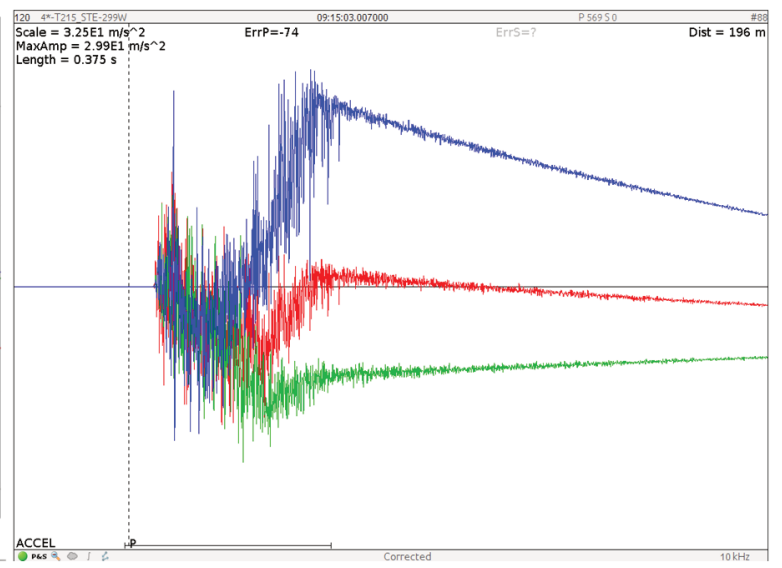

(b)

Figure 3 Sensor clipping due to nearby large events. (a) Geophone waveform displaying displacement clipping (high frequency spikes) and (flat-topped/zeroed) digitiser clipping due to an ML 2.7 event with a hypocentral distance of about $300 \mathrm{~m}$ from the sensor; (b) Piezoelectric accelerometer clipping due to a ML 0.3 event about $56 \mathrm{~m}$ away, showing signal saturation followed by exponential decay of the baseline

So-called 'strong ground motion' (SGM) sensors are commonly used in applications such as earthquake engineering, early warning systems and structural health monitoring. There are many such sensors on the market but few have acceleration ranges beyond $\pm 4 \mathrm{~g}$ or frequency bandwidths wider than $500 \mathrm{~Hz}$. This is an adequate measurement range for far-field monitoring where ground motions and high frequencies decay rapidly with distance, but for the case of in-mine monitoring where sensors may be located tens of metres from, or literally in, the seismic source and therefore subjected to high frequency and amplitude ground motions, this range is grossly inadequate. For example, an acceleration of $4 \mathrm{~g}$ at a frequency of $500 \mathrm{~Hz}$ translates to a ground velocity of only $12.5 \mathrm{~mm} / \mathrm{s}$, which is easily recorded by a standard geophone.

For in-mine monitoring of near-source ground motions, a sensor capable of recording much larger ground motions (less sensitive) at higher frequencies (wider bandwidth) is thus required.

To fulfil this requirement, IMS developed a borehole SGM sensor with a measurement range of $\pm 100 \mathrm{~g}$ $(312 \mathrm{~mm} / \mathrm{s}$ at $500 \mathrm{~Hz}$ ) and a bandwidth of $11 \mathrm{kHz}$. Figure 4 shows a waveform recorded by this sensor together with that of a co-located $4.5 \mathrm{~Hz}$ geophone which clipped during a large event. The recording of the IMS SGM sensor reliably records the peak particle velocity (PPV) of $209 \mathrm{~mm} / \mathrm{s}$ without clipping or saturation. 


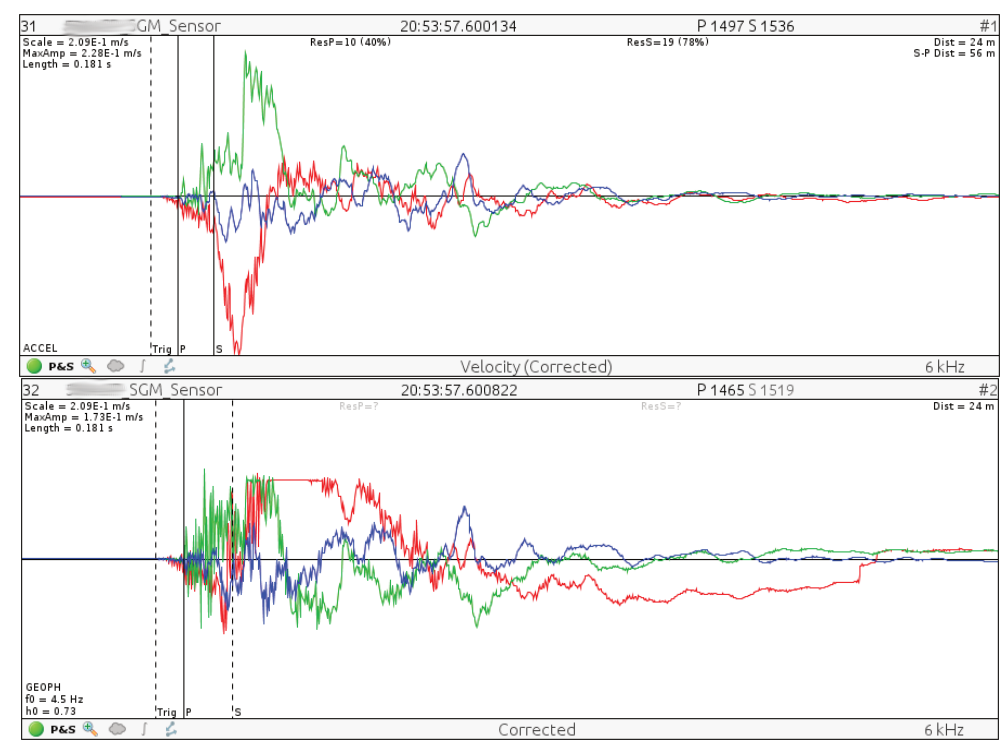

Figure 4 Waveforms recorded by a strong ground motion sensor (top) and co-located geophone (bottom) located $24 \mathrm{~m}$ from a ML 2.2 event. In each case, the red, blue and green traces represent the signals recorded by the $x-, y$ - and $z$-component respectively of the sensor. The geophone displays signs of two kinds of clipping; firstly due to the maximum displacement of the sensing coil being reached and secondly due to the maximum voltage of the analogue-to-digital converter being exceeded. The strong ground motion sensor, on the other hand, records the true ground motion without clipping. The vertical scale of both waveforms is $20 \mathrm{~cm} / \mathrm{s}$

\subsection{Hybrid sensors}

As previous sections have highlighted, in-mine seismic monitoring is a unique application with a wide range of challenging criteria imposed on the sensors of a monitoring system. No single sensor available on the market today meets all of these requirements, and it is not expected that any sensor ever will. To overcome these limitations, a hybrid approach can be adopted where different sensor types are packaged into the same housing. This offers the convenience and cost saving of installing only a single sensor site while gaining the benefits of combining the desirable characteristics of multiple sensors into a single monitoring site.

\subsection{Distributed acoustic sensing}

A new class of seismic sensor based on optical fibre sensing technology is showing potential for both geophysical (Willis et al. 2017), seismological (Zhan 2019) and mine monitoring (Wang et al. 2018) applications. Distributed acoustic sensors (DAS) broadly consist of a fibre optic cable connected to an optical interrogator. The interrogator sends light pulses down the fibre optic cable and processes the light reflected back from intrinsic impurities within the fibre. The dynamic strain rate along the fibre can be derived from the changes in the signals produced by the reflected light. Modern interrogators perform the task of sending light pulses and analysing the reflections fast enough to achieve a spatial resolution of less than $1 \mathrm{~m}$ on optical fibres with lengths of more than a kilometre at sample rates in the audio/microseismic band. This means dynamic strain (seismic) information can be measured from locations along the fibre at effective spacings down to $1 \mathrm{~m}$, as if point sensors were located at every metre of the fibre, hence the distributed nature of the sensor. The measurement bandwidth achievable can span from as low as $0.01 \mathrm{~Hz}$ to more than $1 \mathrm{kHz}$. For a thorough introduction to the fundamental theory and applications of DAS, as well as some of the practical considerations, refer to Hartog (2017).

In my view, the major advantages that DAS provides over conventional seismic sensors are its distributed nature and the fact that the sensing element is the relatively inexpensive and small diameter fibre cable itself. The ability to have hundreds to thousands of virtual sensors spanning kilometres along the sensing fibre 
means that the full seismic wavefield is available for processing and inversion. Installing the same number and density of conventional point sensors would be prohibitively expensive and time consuming. The small diameter (typically less than $15 \mathrm{~mm}$ ) of fibre optic cables used for sensing means that DAS sensors can be installed in space constrained spaces where conventional seismic sensors cannot, e.g. in smaller diameter exploration boreholes.

The notable drawbacks of DAS are its relatively higher signal-to-noise ratio (SNR) compared to geophones, difficultly coupling the fibre to the rock mass, and that DAS is only sensitive to strain changes in the axial direction of the fibre, i.e. DAS is inherently a uniaxial sensor. It should be noted that helically-wound fibre optic cables exist which somewhat overcome the axial sensitivity problem, however, this renders the fibre cable diameter larger to accommodate the helical wind, which means the small diameter advantage is lost. Another challenge which DAS poses, both logistically and scientifically, is managing and processing the vast quantities of data that are produced. Not only are the demands for storage space and facilities exponentially increased compared to conventional monitoring systems, but so too are the required computing resources. New processing methods will need to be developed to handle the increased data volume and rate.

I expect to see an increase in the use of DAS for in-mine seismic monitoring and survey-type applications. As with the other sensors discussed so far, DAS brings certain key advantages to the table, but is not without its challenges. Therefore, using DAS to augment conventional sensors and monitoring systems is expected to produce the best results.

\section{Data acquisition hardware}

Data acquisition hardware is the next level up the hierarchy of a seismic monitoring system. It is responsible for accurately and reliably converting the analogue signals produced by seismic sensors into digital data, which can be ultimately stored for downstream processing.

Acquisition hardware typically operates in one of two modes: either offline and autonomously in a standalone fashion where data is harvested after retrieval of the unit from the field, or online in a supervised manner. The online case typically operates as a network of acquisition units coordinated and controlled by a centralised network controller which coordinates the telemetry and populates a database in near real time, making field data available for downstream processing almost immediately.

\subsection{Nodal sensors}

First used by the petroleum industry and more recently in the fields of volcanology (Brenguier et al. 2016) and crustal seismology (Inbal et al. 2015; Li et al. 2018), the use of inexpensive 'nodal' geophone sensors to establish 'large- $\mathrm{N}$ ' arrays (large, dense arrays consisting of many surface sensors) has become a popular acquisition method for gathering active and passive seismic data sets used primarily in seismic tomography applications. Array processing methods (Li et al. 2018) and ambient noise processing techniques (Bensen et al. 2007) can be used to extract useful data from low SNR data.

Owing to the high global demand created by the exploration industry for millions of such nodal sensors, the cost benefits of mass production has resulted in nodes being available for less than US $\$ 300$ per node.

Nodal sensors, or simply nodes, are completely self-contained, autonomous (standalone), cable-free seismic acquisition units including sensor, digitiser, data storage, battery power and GPS receiver in the same waterproof package. They are designed to be rapidly deployed on surface, record continuous data for a pre-programmed time or until the battery runs out (typically 3-4 weeks) and then retrieved to download the data. While not very useful for permanent monitoring applications, nodes are well suited to temporary survey-type applications where large numbers of nodes can be deployed quickly and inexpensively. This has applications in imaging the rock mass near mining operations (Dales et al. 2020), which can be used to reveal geological structures, detect voids (e.g. old mine workings) or calibrate velocities above a caving operation. Figure 5 shows some pictures of commonly used nodes. 


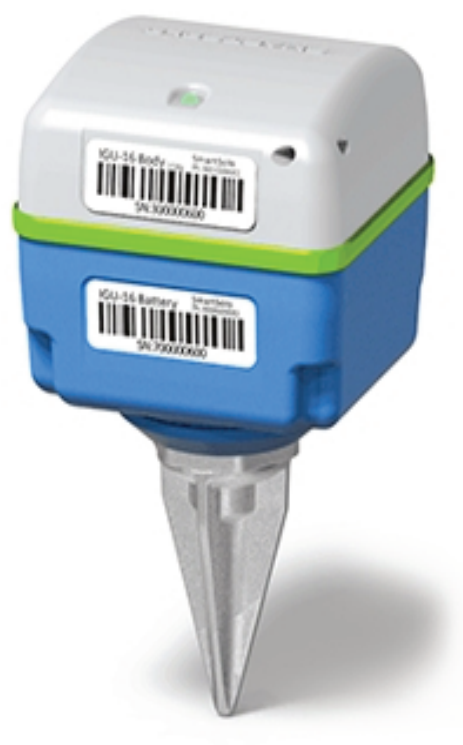

(a)

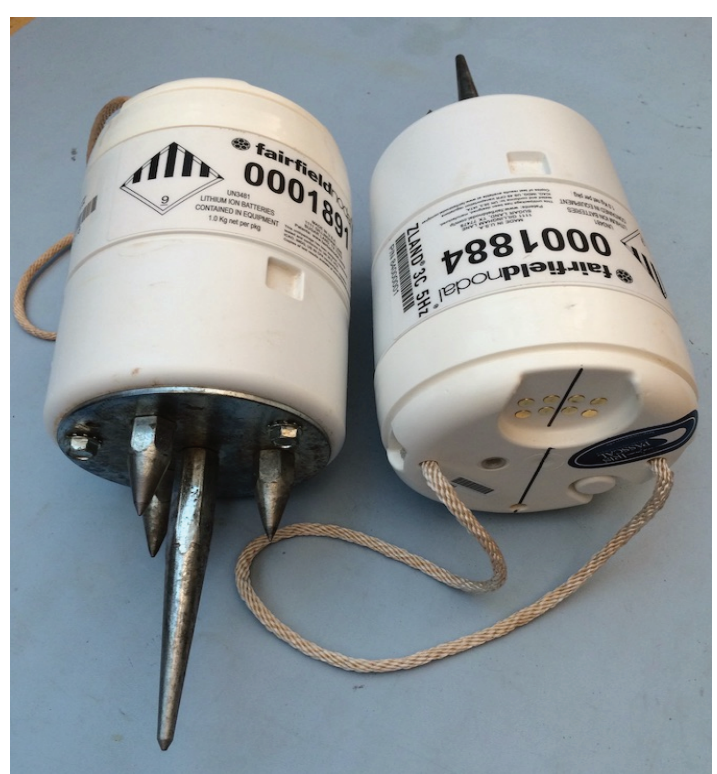

(b)

Figure 5 Examples of two popular nodal sensors. (a) The SmartSolo ${ }^{\circledR}$ uniaxial $5 \mathrm{~Hz}$ node by DTCC (https://smartsolo.com); (b) The ZLAND $\otimes 3 C$ triaxial $5 \mathrm{~Hz}$ node by Fairfield Nodal (https://fairfieldgeo.com)

\subsection{Wireless surface stations}

Nodes are very useful and cost-effective for short-term deployments, e.g. for seismic surveys or temporary surface-based monitoring, but they are not suitable for underground operation (they rely on GPS for time synchronisation) nor are they able to operate online (with real time data transfer) or as permanent deployments (due to no facilities to connect an external power source).

For long-term or permanent seismic monitoring deployments where compact size and low power consumption remain important, e.g. for surface installations where no infrastructure exists, a solar-powered seismic monitoring station with wireless communications and small footprint is desired. This is typically achieved by adding a solar power system and wireless modem to a conventional monitoring station. The footprint of such a system can become large and heavy, requiring cumbersome solar panels and batteries to ensure autonomy of the station during consecutive days with low sunlight hours.

Leveraging the technology advances driven by the nodal sensor market, some manufacturers have developed wireless sensors that combine many of the benefits of nodal sensors (low power, compact size, waterproof, integrated sensor, GPS and data storage) while addressing some of the shortcomings of nodes, specifically by the inclusion of wireless communications as well as facilities for supply of external power. One such wireless sensor made by IMS is shown in Figure 6. 

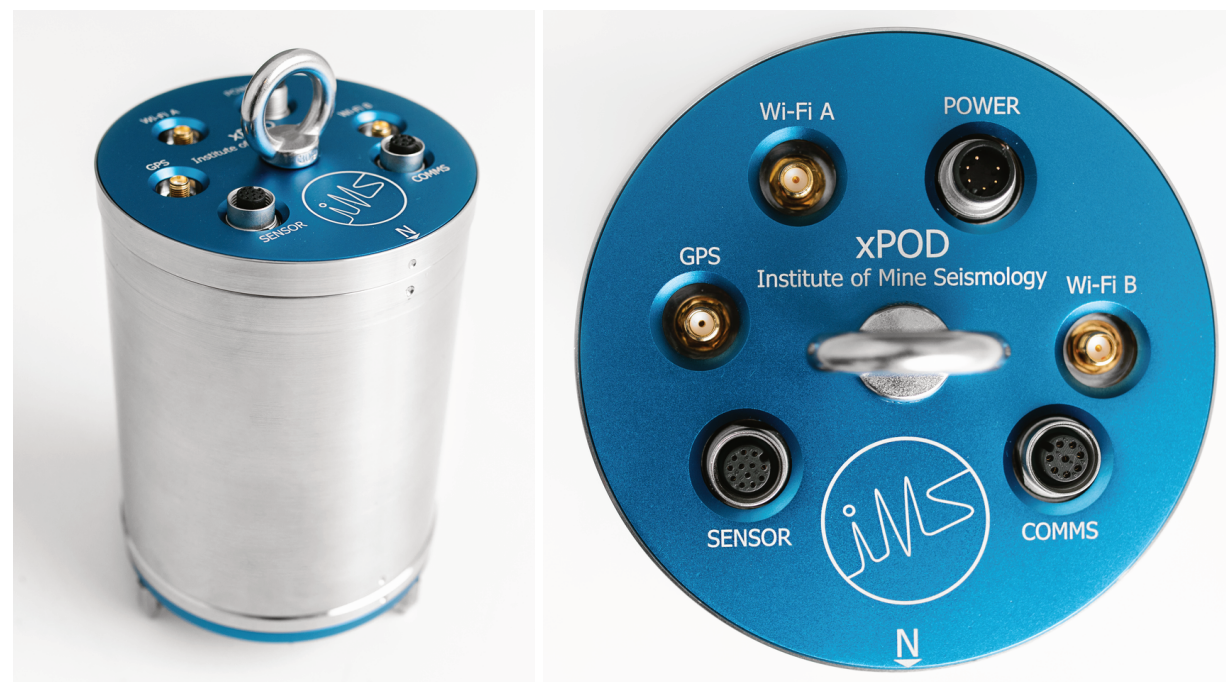

Figure 6 The $x \mathrm{POD}^{\mathrm{TM}}$ by Institute of Mine Seismology (http://www.imseismology.org/sensors) is a compact, low power, self-contained seismic monitoring station (or 'wireless sensor'). It includes an integrated $5 \mathrm{~Hz}$ uniaxial geophone sensor, $129 \mathrm{~dB}$ analogue-to-digital converter, GPS receiver and data storage. External connections allow for permanent deployments by connecting a small solar power system and Wi-Fi antennas

The benefits of wireless seismic acquisition units, which combine the useful characteristics of nodal sensors with the ability to be deployed permanently and online for real time acquisition, mean that deployments of remote monitoring stations in the field are easier and require little site preparation, excavation/civil works or permissions due to the low power and physically small footprint of the device. Only a small solar power system ( $40 \mathrm{~W}$ panel) and shallow posthole are required to commission these units in contrast to large concrete pads or vaults required for conventional monitoring stations. The units are well-suited to surface monitoring applications where sensors are placed kilometres from the mine (often not on the mine owner's land) to capture the far-field seismic waves generated by mining-induced or regional tectonic events. Remote surface sites are often located in environmentally sensitive areas, requiring permits for any significant works to be undertaken. Another application for which these devices are well suited is tailings dam monitoring (Olivier et al. 2017, 2018; de Wit \& Olivier2018), where a lack of infrastructure requires a self-contained solution and small installation footprint without the need for trenching of cables are essential.

\subsection{Vibration monitoring}

Seismic monitoring is primarily focussed with the characterisation of seismic sources. Parameters of the source are inverted by using a number of remote observations (obtained from sensor waveforms) and physical models used to estimate the seismic event's location, size, seismic moment, energy, mechanism, etc. (Mendecki 1997).

Certain geotechnical applications, however, require monitoring of ground motions, not for the characterisation of the seismic source itself, but to measure its effects on infrastructures or assets which may experience ground motions as a result of seismic events. In many ways, this is a simpler problem than seismic monitoring as it does not involve much processing or inversion for the seismic source and often only measures certain statistical parameters of triggered waveforms (e.g. PPVs), but it is equally important, for example, to monitor the performance of existing and to plan for future ground support. There may also be compliance requirements that ground vibrations and air overpressure be monitored during blasting as mandated by local or national authorities according to standards such as Standards Australia (2006), United States Bureau of Mines (USBM) 1989, International Society of Explosives Engineers (2017) or Deutsches Institut für Normung (2019). 
Vibration monitoring surveys are often undertaken on a once-off or short-term basis, e.g. at a specific distance from a specific blast sequence. The equipment used for such surveys therefore needs to be portable and user friendly and able to be rapidly deployed and retrieved. Compliance reporting, if required, is mainly offline where data are downloaded at a workstation and reports generated according to the relevant standard.

The requirements of vibration monitoring (e.g. blast monitoring) bring their own set of unique challenges which most seismic monitoring systems do not cater for. A system needs to be portable and user friendly which, due to the complexity of seismic monitoring systems, is often not the case. Most vibration monitoring standards/regulations require regular (annual) calibration of sensors and acquisition hardware to ensure measurements are within tightly defined specifications, while seismic monitoring is more forgiving in this regard as the errors in the inversion process are generally orders of magnitude greater than the errors in acquisition sensors and hardware. As such seismic monitoring equipment is generally calibrated at the factory (if at all) and never again.

Figure 7 shows some examples of commonly used vibration monitoring units specifically designed for blast monitoring.

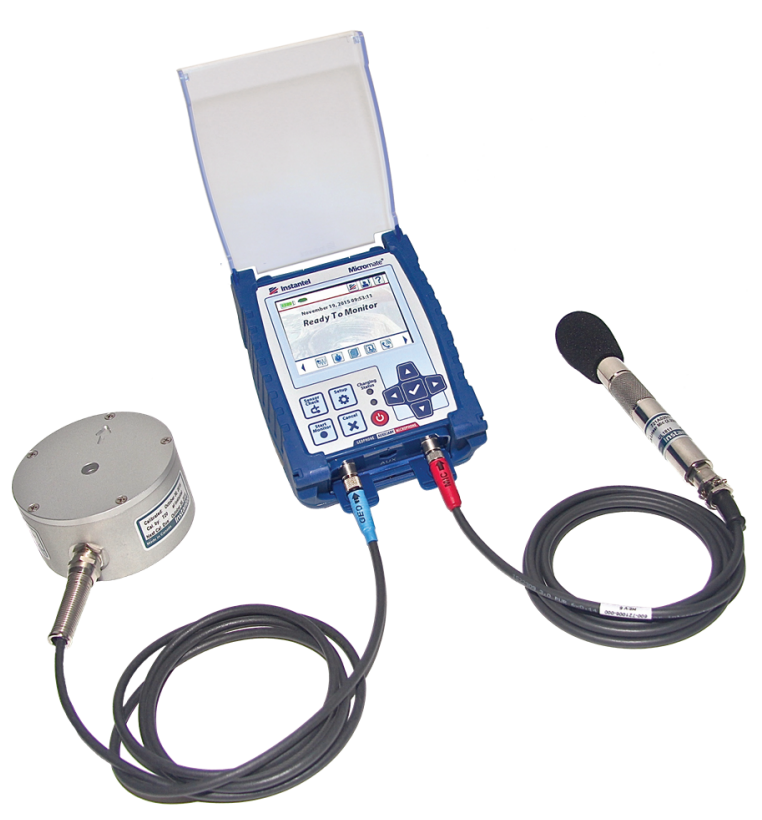

(a)

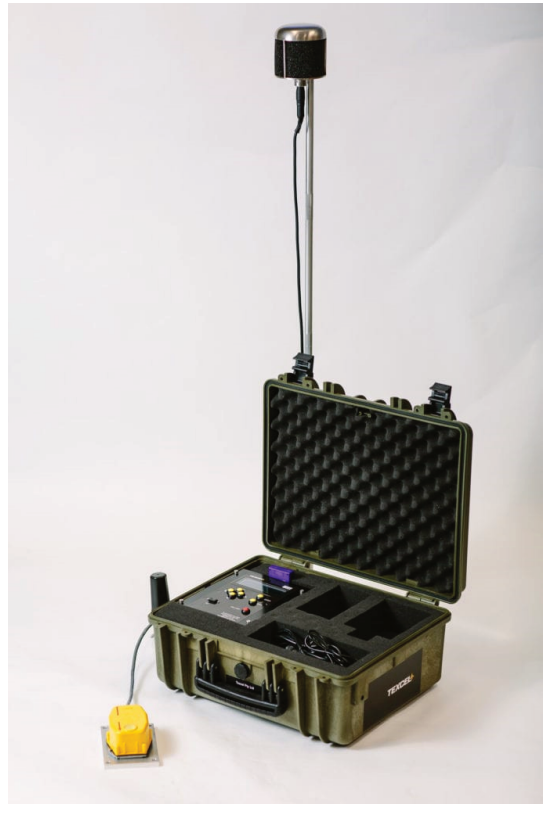

(b)

Figure 7 Examples of two popular vibration (blast) monitoring units. (a) The Micromate ${ }^{\circledR}$ by Instantel (https://www.instantel.com); (b) The Environmental Texcel Monitor by Texcel (https://texcel.com.au)

Historically, conventional vibration monitoring systems have not been well-suited to seismic monitoring applications. For example, they typically lack the ability to synchronise data acquisition timing between units and online real time functionality is limited, if at all possible. Limited memory and processing resources, while increasing battery life, means they are unable to record full waveforms and/or continuous data for extended periods of time. The result is that geotechnical engineers either have to operate and maintain two systems (one for monitoring seismicity and another for any vibration monitoring compliance) or use a sub-optimal tool.

To address this problem, manufacturers are beginning to add features to vibration monitoring systems which allow them to be used as both vibration (blast) monitors as well as seismic monitoring stations simultaneously. The advantages are that a mine only needs to operate a single system where data suitable for both applications is stored in a common database. The portable and user friendly features of vibration monitors are combined with the more feature-rich signal processing, timing and connectivity functionality of 
seismic monitoring systems to produce a hybrid monitoring system. An example of such a system made by IMS is shown in Figure 8.

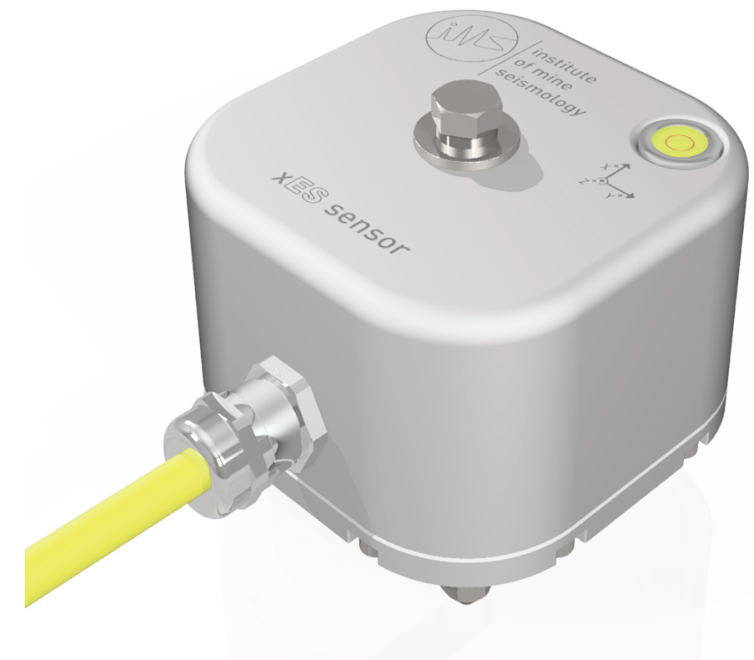

(a)

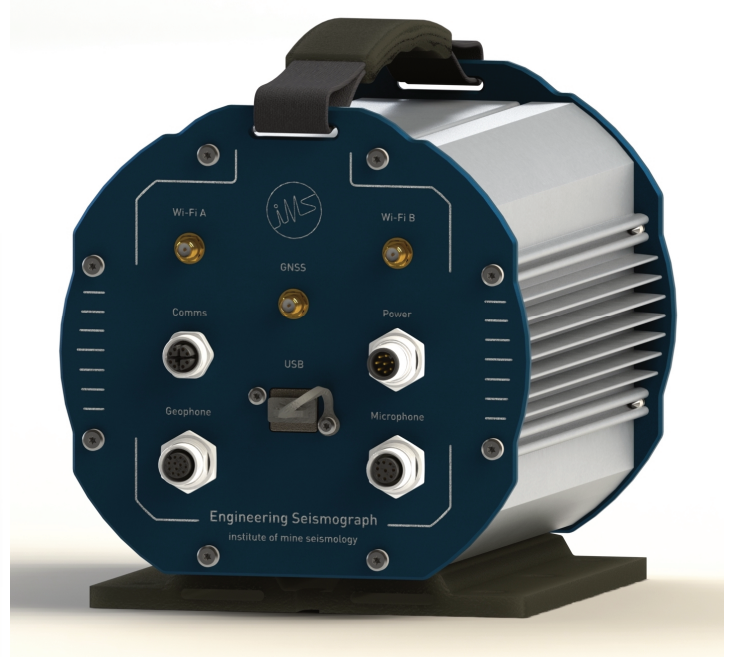

(b)

Figure 8 Preliminary impressions of the Institute of Mine Seismology. (a) XES ${ }^{\mathrm{TM}}$ vibration monitoring sensor and (b) Engineering Seismograph; a compact, portable, low power and self-contained data acquisition unit meeting the needs of vibration and seismic monitoring applications. It includes an integrated battery, GPS receiver, processor and data storage. External connections allow for connection of external sensors, communications, power and additional USB storage. The XES can be used in permanent deployments for realtime online monitoring or the internal battery means it can operate in standalone offline mode (http://www.imseismology.org/)

\section{$4 \quad$ Applications}

\subsection{Case study: in-mine hydraulic fracture monitoring}

In 2019, a dense array of sensors were installed in four monitoring boreholes, concentrated around the injection boreholes of a hydraulic fracturing project in a large mine. The objective of the hydraulic fracturing was to soften a particular region of the rock mass, reducing the expected energy released from sudden episodes of shear deformation. The monitoring boreholes were all drilled from the same mining level about $1 \mathrm{~km}$ below surface and sensors were installed at distances from collar ranging from $10-130 \mathrm{~m}$. A combination of 25,10 and $3.7 \mathrm{kHz}$ accelerometers were chosen to monitor the smaller magnitude events expected to be generated. The mine had an existing mine-wide geophone array, which was expected to be useful in characterising source parameters and mechanisms of large events but not sensitive enough to trigger on the smaller induced events with higher frequency content.

The objective of the monitoring project was to monitor the extent and geometry of hydraulically-induced fractures as well as the possible re-activation of new and existing structures. Figure 9 shows the sensor array and an example of locations of smaller magnitude events detected by the dense accelerometer array during an active injection period. Figure 10 shows how the locations of the events clearly delineate two previously known geological structures. Figure 11 shows source mechanisms and stereonet of the larger events obtained using waveforms of the mine-wide geophone array, which show good correlation with the known structure orientation. Combining these two datasets, i.e. locations of the large number of smaller 'accelerometer' events and source mechanisms of the larger magnitude 'geophone' events, therefore provides complimentary and corroboratory evidence of the geological structures. 


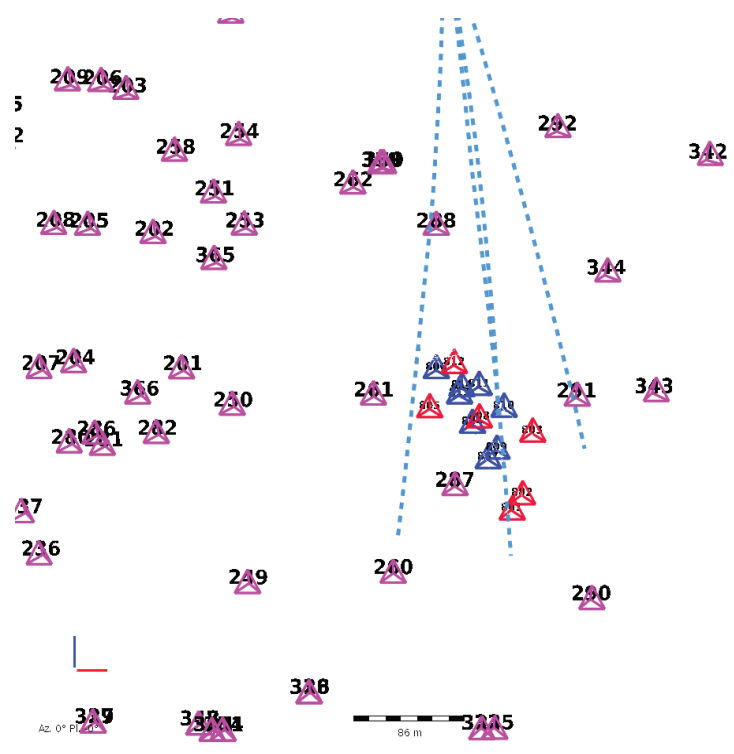

(a)

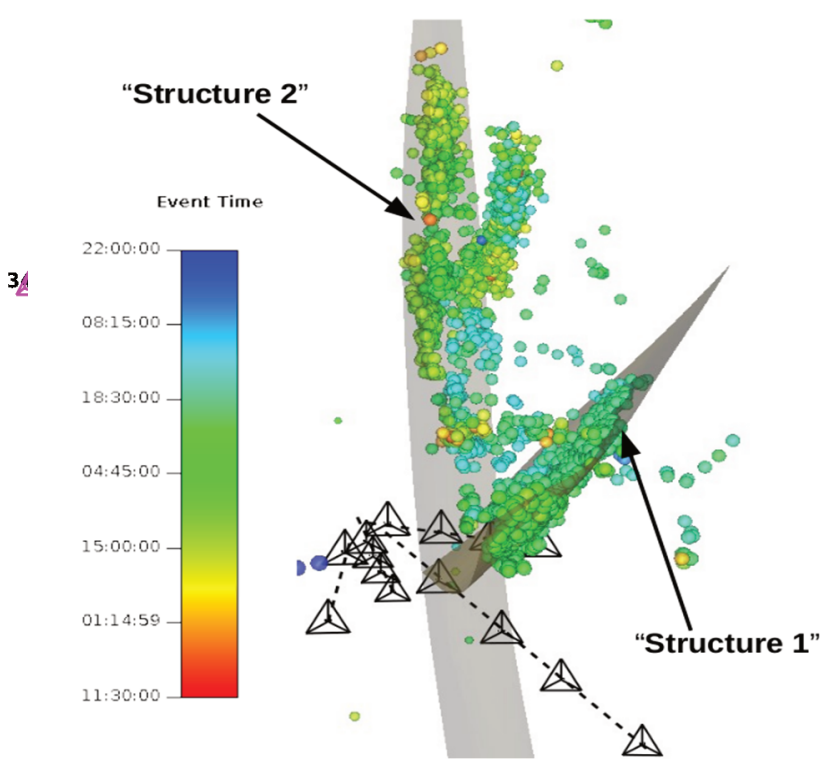

(b)

Figure 9 Hydrofracture monitoring array and event locations. (a) Pink sensors are part of the existing mine-wide geophone array, red and blue sensors are a dense network of accelerometers installed around the injection sites; (b) Locations of events recorded by the accelerometer array during a 60-hour period while injection was active. Events are represented by spheres coloured by time (see legend). Sphere sizes are arbitrary but equal, and independent of magnitude so as to emphasise location
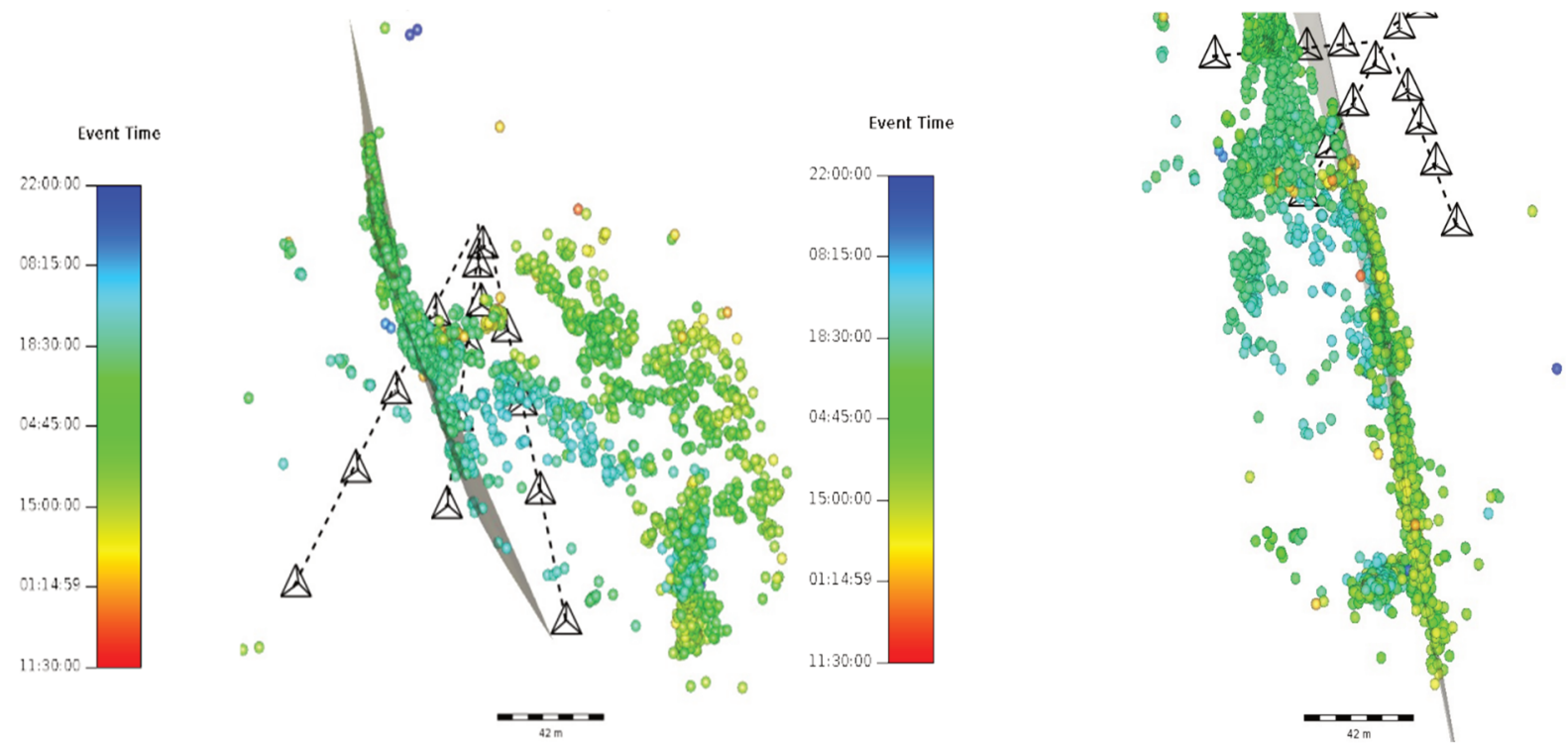

Figure 10 Separate views of locations of events recorded by the accelerometer array during a 60-hour period while injection was active. Events are represented by spheres and coloured by time (see legend). Sphere sizes are arbitrary but equal, and independent of magnitude so as to emphasise location. Two separate known geological structures are shown, which the location of the events clearly delineate 


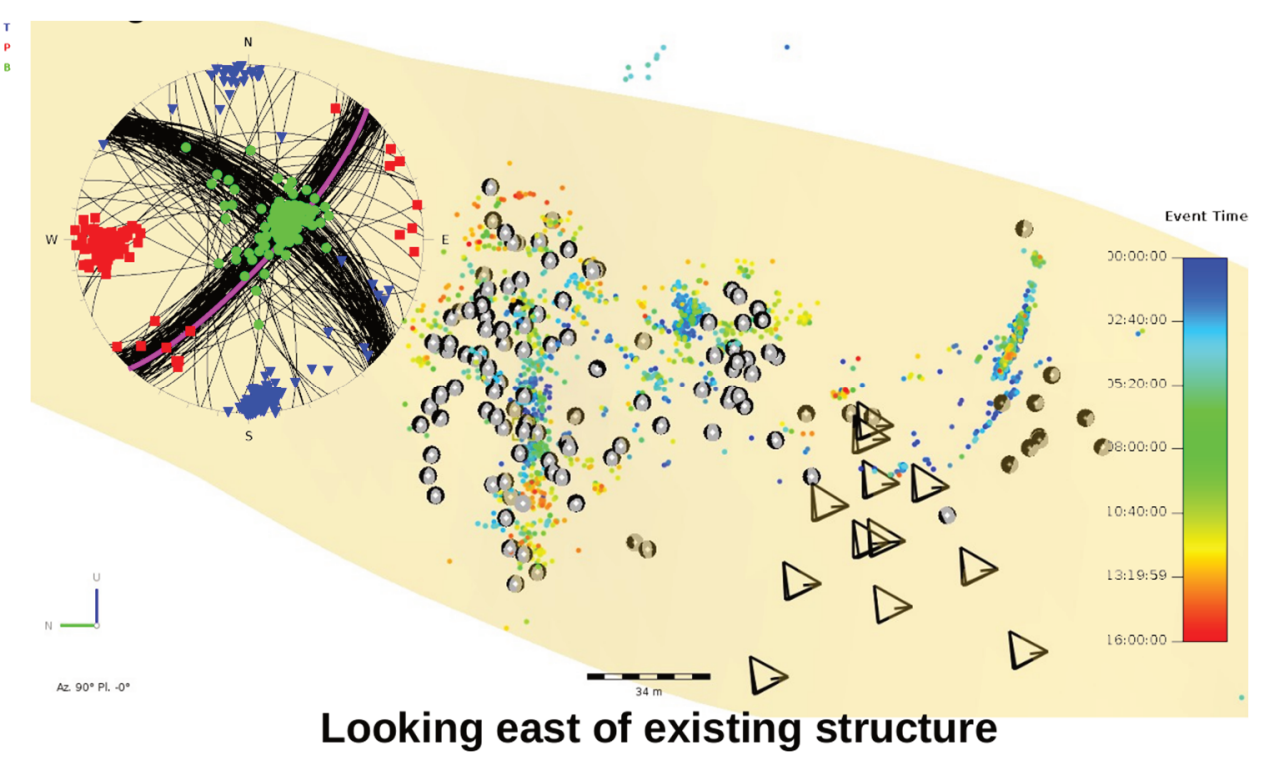

Figure 11 Source mechanisms and stereonet of the larger events obtained using waveforms of the mine-wide geophone array during the same 60 -hour period while injection was active. Events with source mechanisms are shown with beach balls of equal but arbitrary size (independent of magnitude). Events without mechanisms are shown as dots coloured according to time (see legend)

Figure 12 shows the size distribution of events recorded by the accelerometer and geophone arrays, processed separately but for the same time period. The vertical bars represent a histogram distribution of event moment magnitudes, binned with $\Delta \mathrm{M}_{\mathrm{w}}=0.1$, while the spheres represent the cumulative number of events with a moment magnitude greater than or equal to the corresponding value on the $x$-axis. The accelerometers recorded 10 times more events than the geophones. In fact, this factor was closer to 20 but the distribution only uses events for which source parameters could be calculated. The $\mathrm{M}_{\text {wmin }}$ for the accelerometers is -2.5 and -1.0 for the geophones, which bears testament to the improved sensitivity of accelerometers to the higher frequencies radiated by nearby smaller events. However, the saturation of the accelerometers at higher moment magnitudes $\left(M_{w}>-1.0\right)$ highlights the need for geophones at sufficient distance which can record, with adequate signal-to-noise ratios, the signals generated by events of larger moment magnitudes and lower frequency content.

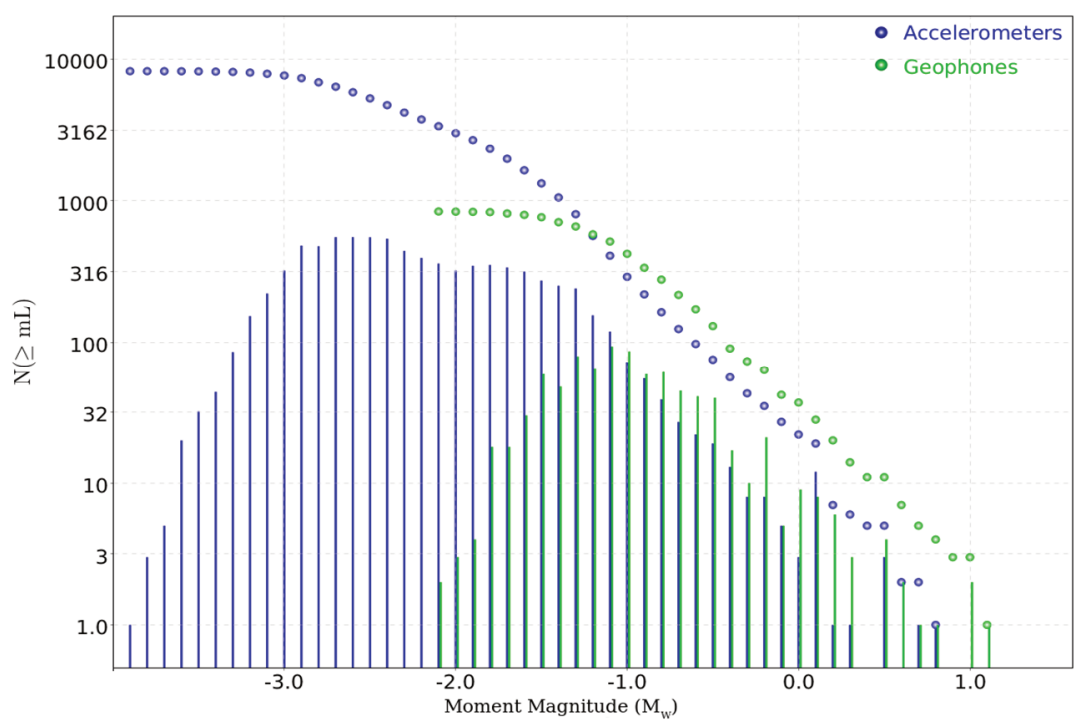

Figure 12 Size distribution of events recorded by the accelerometers and geophones for the same time period. The distribution uses 8,242 events for the accelerometers and 840 for the geophones 


\subsection{Distributed acoustic sensing trial in a mine}

To investigate the suitability of DAS for seismic monitoring in mines, IMS installed a fibre optic cable in a $200 \mathrm{~m}$ borehole in a mine, co-located with four geophones. Both geophones and DAS were set to record continuous data for 2 weeks. During this time, 10 events were recorded in the vicinity of the fibre of which only four were 'detectable' in the DAS data. Figure 13 shows the experiment and an example waveform recorded by geophone and DAS during one of the events.

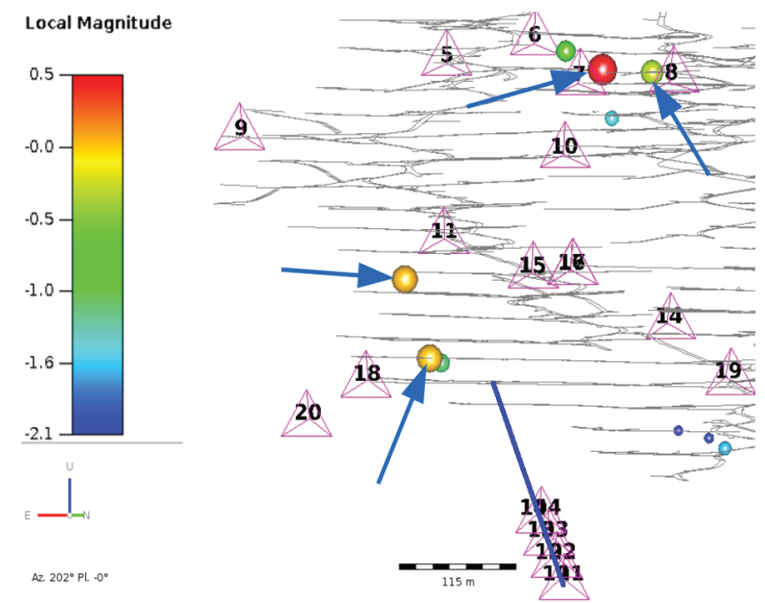

(a)

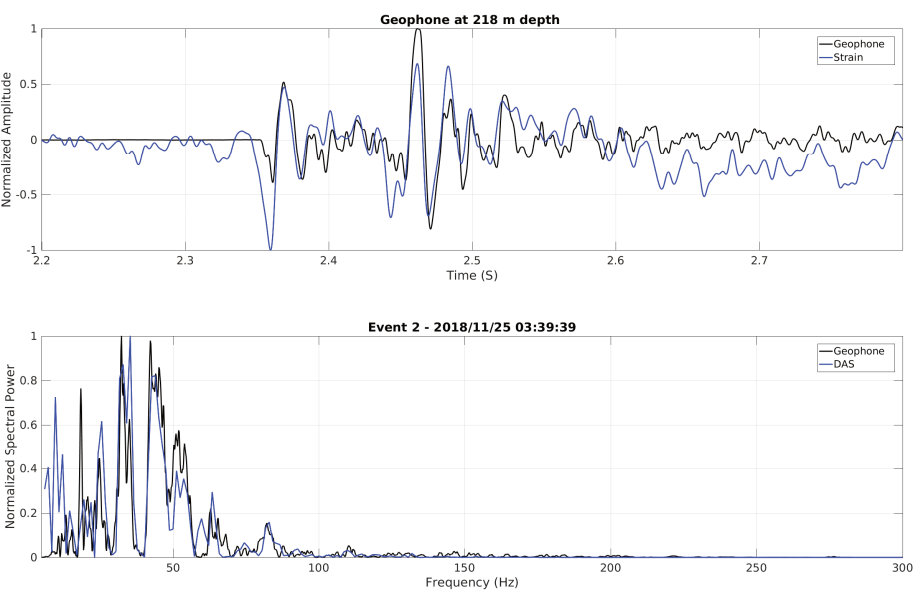

(b)

Figure 13 Fibre optic cable installed alongside four geophones in a $200 \mathrm{~m}$ borehole in an underground mine. (a) Distributed acoustic sensors (DAS) trial array configuration showing the DAS borehole (blue line with four geophone sites 101-104 at bottom of picture). Spheres are 10 events that occurred during the trial period. Events with blue arrows were detectable by the DAS. (b) Waveforms and spectra recorded by a geophone (black) and the virtual DAS sensor at the same location as the geophone (blue) during one of the events in (a)

Figure 14 demonstrates the distributed nature of the DAS sensor and provides an appreciation for the depth and volume of information provided by a distributed sensor. The DAS data is clearly noisier than the geophone data, but unlike the geophones which are point sensors, the DAS sensor captures the entire wavefront as it moves past the length of the fibre.

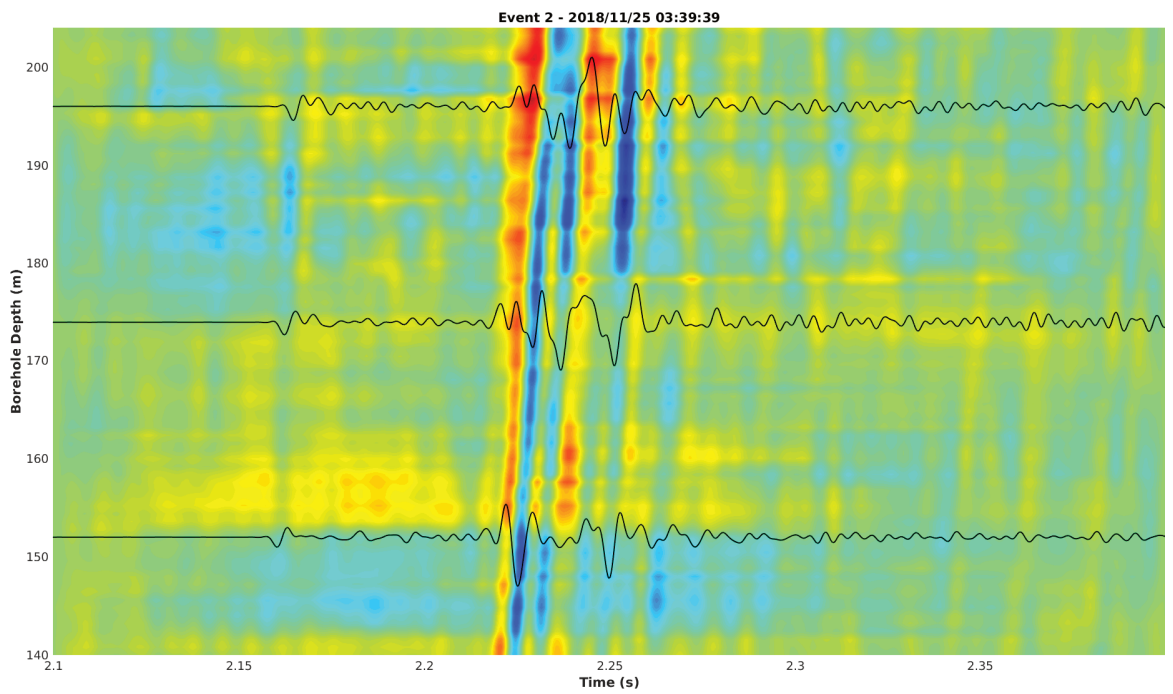

Figure 14 Waterfall plot of distributed acoustic sensors recording during a seismic event; colour represents signal amplitude. Geophone data recorded by three co-located geophones are overlayed as black lines 


\subsection{Mineral exploration using surface nodal array and in-mine seismic system}

The long-term sustainability issues faced by the mining industry are driving a need for more innovative exploration techniques to keep up with the demand for new discoveries. The development of new technologies and increase in processing ability for large datasets have allowed for passive seismic methods to become a feasible option for exploration (Dales et al. 2020; Hollis et al. 2018).

In December 2018, IMS installed 200 nodal geophones adjacent to an operating underground mine to test new passive seismic imaging methods. These methods do not require an active source and use mining-induced earthquakes and background noise to image the subsurface. The configuration of nodal surface geophones (blue) and in-mine geophones (pink) are shown in Figure 15, and some examples of data recorded by the arrays appears in Figure 16. Some results of inverting for the S-wave velocities using the data collected from the surface and in-mine arrays is shown in Figure 17.

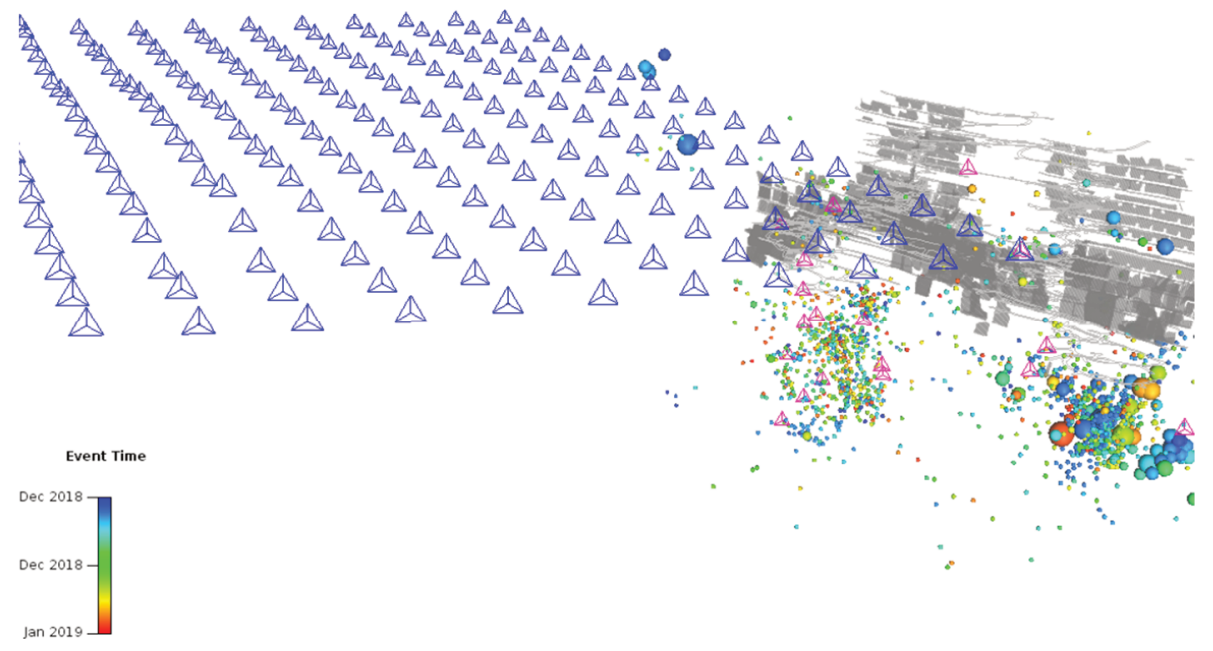

Figure 15 Perspective view of the hybrid array used for near-mine imaging of geological structures. Blue sensors (top left) are an array of 200 nodal geophones installed on surface. The mine workings, events and seismic monitoring system (pink sensors) are shown on the right

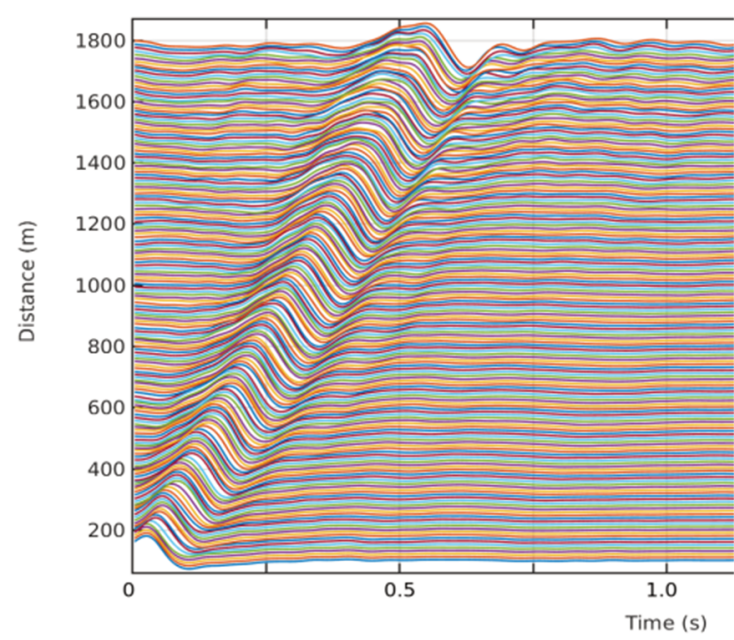

(a)

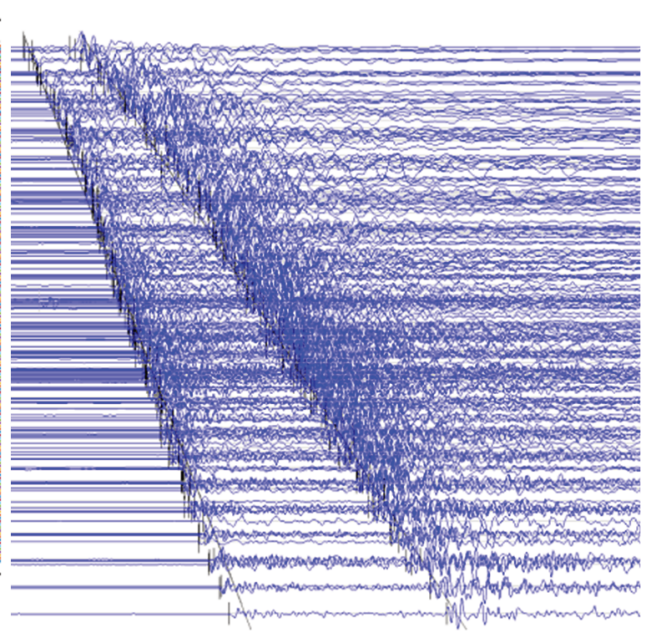

(b)

Figure 16 (a) Surface waves extracted by cross-correlating ambient noise recorded by the surface nodal array; (b) A mining-induced event recorded by the mine and nodal array 


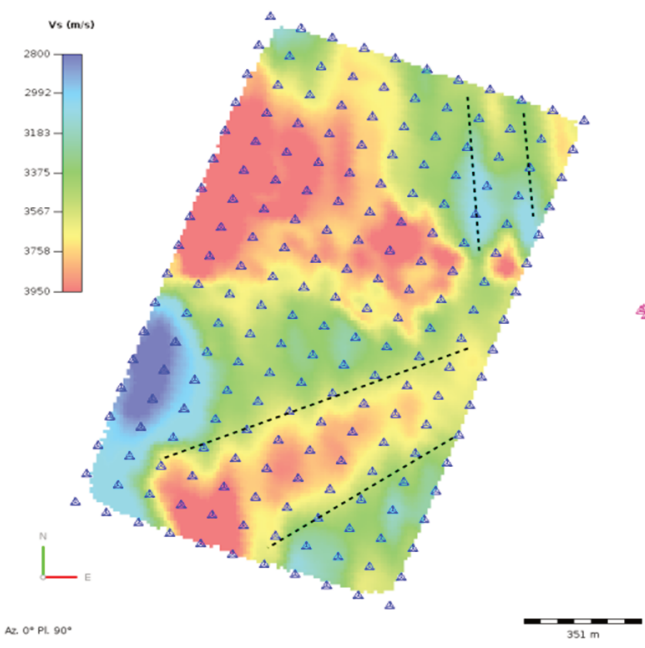

(a)

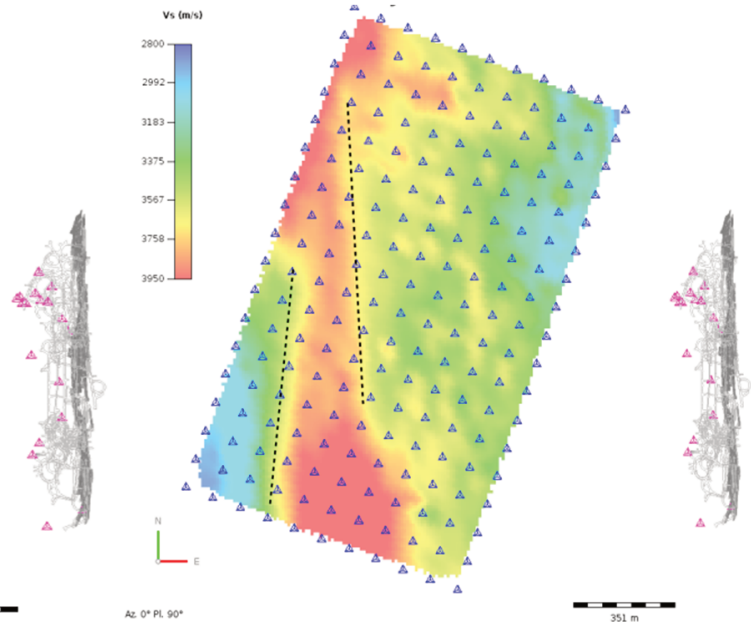

(b)

Figure 17 Results of processing the ambient noise and mining-induced events to perform a joint inversion of shear wave velocities. (a) Cross-section of S-wave velocity $150 \mathrm{~m}$ below surface; possible structures shown dashed. (b) Cross-section of S-wave velocity $350 \mathrm{~m}$ below surface; possible structures shown dashed

The data resulting from this survey enabled high resolution imaging of the dominant structures in the region up to $700 \mathrm{~m}$ depth, which ultimately aided in targeting areas for subsequent drilling campaigns.

\section{Conclusion}

In the last decade, there have been a number of significant and exciting advances in seismic monitoring technologies. Perhaps the common theme is the availability of new types of low cost sensors, from low noise wide bandwidth accelerometers to nodal geophone sensors and distributed optical sensors. All have a role to play, but no single technology is a panacea. It is when the various technologies are combined in hybrid arrays where the maximum benefit is realised.

Inspired by the advances of the last decade, industry continues to innovate and the next decade will likely see a refinement of the technologies, which are starting to become mature.

\section{Acknowledgement}

Stephen Meyer provided the images and seismological results for the hydrofrac case study. Mark Green and Dolf Bredenkamp provided the images of DAS trial. Gerrit Olivier leads the IMS geophysics group and provided the images and results for the mineral exploration application section. Ernest Lötter and Daryl Rebuli helped with images of waveforms. Many of my colleagues at IMS, but particularly Dmitriy Malovichko and Stephen Meyer, provided reviews of the seismological content.

\section{References}

Bensen, G, Ritzwoller, M, Barmin, M, Levshin, A, Lin, F, Moschetti, M...\& Yang, Y 2007, 'Processing seismic ambient noise data to obtain reliable broad-band surface wave dispersion measurements', Geophysical Journal International, vol. 169, pp. 1239-1260.

Brenguier, F, Rivet, D, Obermann, A, Nakata, N, Boué, P, Lecocq, T...\& Shapiro, N 2016, '4-D noise-based seismology at volcanoes: ongoing efforts and perspectives', Journal of Volcanology and Geothermal Research, vol. 321, pp. 182-195.

Dales, P, Pinzon-Ricon, L, Brenguier, F, Boué, P, Arndt, N, McBride, J...\& Olivier, G 2020, 'Virtual sources of body waves from noise correlations in a mineral exploration context', Seismological Research Letters, vol. 91, no. 4 pp. 2278-2286.

Deutsches Institut für Normung 2019, Measurement of Vibration Immissions - Part 1: Vibration meters - Requirements and Tests (DIN 45669-1:2019-09), DIN Deutsches Institut für Normung, Berlin. 
de Wit, T \& Olivier, G 2018, 'Imaging and monitoring tailings dam walls with ambient seismic noise', in RJ Jewell \& AB Fourie (eds), Proceedings of the 21st International Seminar on Paste and Thickened Tailings, Australian Centre for Geomechanics, Perth, pp. 455-464.

Goldswain, G 2018, 'The IMS Seismic Monitoring System', in X Feng (ed.), Rockburst Mechanisms, Monitoring, Warning and Mitigation, Butterworth-Heinemann, Oxford.

Hartog, AH 2017, An Introduction to Distributed Optical Fibre Sensors, CRC Press, Boca Raton.

Hollis, D, McBride, J, Good, D, Arndt, N, Brenguier, F, \& Olivier, G 2018, 'Use of ambient noise surface wave tomography in mineral resource exploration and evaluation', SEG Technical Program Expanded Abstracts 2018, Society of Exploration Geophysicists, Tulsa, pp. 1937-1940.

Inbal, A, Clayton, R \& Ampuero, J 2015, 'Imaging widespread seismicity at midlower crustal depths beneath Long Beach, CA, with a dense seismic array: Evidence for a depth-dependent earthquake size distribution', Geophysical Research Letters, vol. 42, pp. 6314-6323.

International Society of Explosives Engineers 2017, ISEE Performance Specifications for Blasting Seismographs, International Society of Explosives Engineers, Cleveland.

Li, Z, Peng, Z, Hollis, D, Zhu, L, \& McClellan, J 2018, 'High-resolution seismic event detection using local similarity for large-N arrays', Scientific Reports, vol. 8, no. 1646.

McGarr, A 1991, 'Observations constraining near-source ground motion estimated from locally recorded seismograms', Journal of Geophysical Research, vol. 96, no. B10, pp. 16,495-16,508.

Mendecki, A 1997, Seismic Monitoring in Mines, Chapman \& Hall, London.

Mendecki, A 2013, 'Frequency range, logE, logP and magnitude', in D Malovichko \& A Malovichko (eds), Proceedings of the 8th International Symposium on Rockbursts and Seismicity in Mines, Geophysical Survey of Russian Academy of Sciences, Obninsk, and Mining Institute of Ural Branch of Russian Academy of Sciences, Perm, pp. 167-173.

Olivier, G, Brenguier, F, de Wit, T \& Lynch, R 2017, 'Monitoring the stability of tailings dam walls with ambient seismic noise', The Leading Edge, vol. 36, no. 4, pp. 282-368.

Olivier, G, de Wit, T, Brenguier, F, Bezuidenhout, L \& Kunjwa, T 2018, 'Ambient noise Love wave tomography at a gold mine tailings storage facility', Géotechnique Letters, vol. 8, no. 3, pp. 1-17.

Rebuli, D, Goldswain, G \& Lynch, R 2017, 'High Quality Microseismic Monitoring in Mines: Accelerometers or Geophones?', in J Vallejos (ed), Proceedings of the 9th International Symposium on Rockbursts and Seismicity in Mines, Santiago, pp. 23-31.

Standards Australia 2006, Australian Standard Explosives - Storage and use Part 2: Use of explosives (AS 2187.2-2006), Standards Australia, Sydney.

United States Bureau of Mines 1989, Report of Investigations 8507 (RI 8507) - Structure Response and Damage Produced by Ground Vibration from Surface Mine Blasting, Pittsburgh.

Wang, H, Fratta D, Lord N, Zeng X \& Coleman, T 2018, 'Distributed acoustic sensing (DAS) field trials for near-surface geotechnical properties, earthquake seismology, and mine monitoring', SEG Technical Program Expanded Abstracts 2018, Society of Exploration Geophysicists, Tulsa, pp. 4953-4957.

Willis, M, Ajo-Franklin, J \& Roy, B 2017, 'Special Section: Geophysical applications of fiber-optic distributed sensing', The Leading Edge, vol. 36, no. 12 .

Zhan, Z 2019, 'Distributed acoustic sensing turns fiber-optic cables into sensitive seismic antennas', Seismological Research Letters, vol. 91, no. 1, pp. 1-15. 